\title{
Selection of Error Metric for Accurate Characterization of a Thin Dielectric or Semiconductor Film on Glass Substrate by the Optimizing Envelope Method
}

\author{
R.N. Nestorov \\ Department of Microelectronics, Faculty of Electronics Engineering and Technologies, Technical University of Sofia, \\ bul. Kliment Ohridski 8, Sofia 1000, Bulgaria
}

\begin{abstract}
The Optimizing Envelope Method (OEM) for thin film characterization has been based on minimization of an Error Metric (ERM) related to the film thickness or/and the interference order numbers of the extrema in the interference pattern of transmittance spectrum $T(\lambda)$ of the film on glass substrate specimen. It has been indicated that the OEM has a capacity for providing most accurate characterization of almost every dielectric or semiconductor film with average thickness of [300,5000] nm, only from $T(\lambda)$, compared to all the other methods for characterization of such films only from $T(\lambda)$. However, there was no comprehensive analysis of which ERM is best for the OEM. In the presented paper is studied the performance of seven ERMs. An approach based on using grouped bar charts is proposed for selection of the ERM providing the most accurate possible thin film characterization by the OEM, depending on the appearance of $T(\lambda)$.
\end{abstract}

Keywords: best error metric, selection, optimizing envelope method, thin film, optical characterization

\section{I.INTRODUCTION}

Light transmitting thin dielectric and semiconductor films are widely used in optoelectronics, optics, electro-optics, and magneto-optics [1,2]. Accurate characterization of the optical characteristics of such films is needed due to the variety of technologies and technology parameters used for their preparation [3].

A film for optical characterization is very often deposited onto a glass substrate in order to avoid stress and deformation $[1,4]$. The normal incidence transmittance spectrum of a specimen consisting of a thin film on a glass substrate, in the UV/VIS/NIR spectral region of wavelengths $\lambda$, is symbolized as $T(\lambda)$ in this paper. A sketch of such specimen and its main optical characteristics is illustrated in Fig. 1.

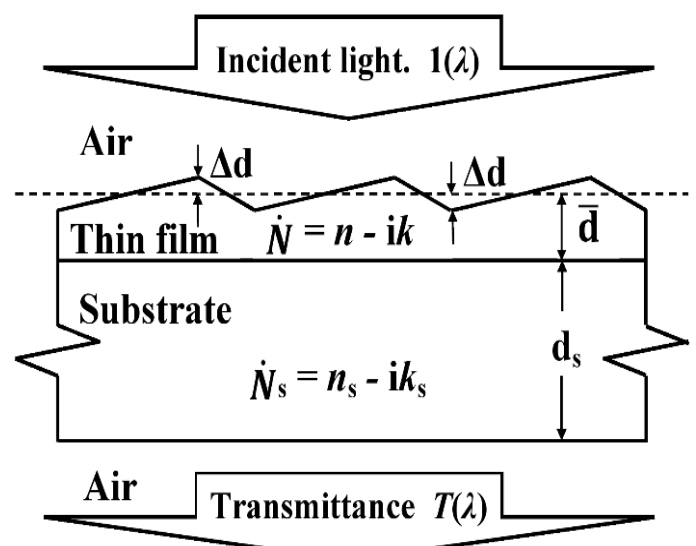

Figure 1. A sketch of a thin film on glass substrate specimen. $\overline{\mathrm{d}}$ is the average film thickness, the thickness non-uniformity $\Delta \mathrm{d} \geq 0$ is the maximum deviation of the film thickness from $\overline{\mathrm{d}}$ over the light spot on the surface film/air, as $n(\lambda)$ and $k(\lambda)$ are the refractive index and the extinction coefficient of the film.

Notably, $T(\lambda)$ of a specimen consisting of a dielectric or semiconductor film with average thickness $\overline{\mathrm{d}}=[300,5000] \mathrm{nm}$ on a glass substrate usually contains interference pattern with several maxima and minima [2]. It turns out that optical characterization of such film can be performed only from the interference spectrum $T(\lambda)$ of the specimen, without employing any dispersion model about the refractive index $n(\lambda)$ or/and the extinction coefficient $k(\lambda)$ of the film [5,6]. 


\section{International Advanced Research Journal in Science, Engineering and Technology}

Vol. 7, Issue 3, March 2020

Such dispersion model free characterization is especially beneficial for doped or mechanically stressed films, since dispersion models can fail for such films [7].

The envelope method (EM) is a dispersion model free method for optical characterization of a film, using the upper envelope $T_{+}(\lambda)$ and the lower envelope $T_{-}(\lambda)$ of the smoothed spectrum $T_{\mathrm{sm}}(\lambda)$ of $T(\lambda)$ [8]. The tangency wavelengths $\lambda_{\mathrm{t}}$ represent the tangency points $T_{\mathrm{sm}}\left(\lambda_{\mathrm{t}}\right)$ between the two envelopes and $T_{\mathrm{sm}}(\lambda)$. Importantly, the EM from its founding paper of Swanepoel [8] is the most cited method for optical characterization of thin films according to Google Scholar data [9]. The EM using only $T(\lambda)$ has three main versions: the founding EM (FEM) of Swanepoel [8] with over 4300 citations, the improved EM (IEM) [10], and the optimizing EM (OEM) [11]. However, in [8] and its modifications [12-17] is considered only the approximation of a film with uniform thickness.

Every EM version is based on a formula for $T_{\mathrm{sm}}(\lambda)$, and an interference fringes equation referring to each $\lambda_{\mathrm{t}}(\mathrm{i})$. The most accurate formula for $T_{\mathrm{sm}}(\lambda)$ is used in [11], and is rewritten as:

$T_{\mathrm{sm}}(\lambda)=\frac{1}{\varphi_{2}-\varphi_{1}} \int_{\varphi_{1}}^{\varphi_{2}} \mathrm{~d} T_{\mathrm{u}}(\varphi)=\frac{\left(\tau_{\mathrm{a}, \mathrm{f}} \tau_{\mathrm{f}, \mathrm{s}} \tau_{\mathrm{s}, \mathrm{a}}\right)^{2} x_{\mathrm{s}}}{\varphi_{2}-\varphi_{1}} \int_{\varphi_{1}}^{\varphi_{2}} \frac{x \mathrm{~d} \varphi}{a_{1}-b_{1} \cos (\varphi)+c_{1} \sin (\varphi)}$,

where

$$
\begin{aligned}
& \varphi=4 \pi n d / \lambda, \varphi_{1}=4 \pi n(\overline{\mathrm{d}}-\Delta \mathrm{d}) / \lambda, \varphi_{2}=4 \pi n(\overline{\mathrm{d}}+\Delta \mathrm{d}) / \lambda, x=\exp (-4 \pi k d / \lambda), x_{\mathrm{s}}=\exp \left(-4 \pi k_{\mathrm{s}} \mathrm{d}_{\mathrm{s}} / \lambda\right), \\
& a_{1}=1-\left(\rho_{\mathrm{a}, \mathrm{f}} \rho_{\mathrm{s}, \mathrm{a}} x x_{\mathrm{s}}\right)^{2}+\rho_{\mathrm{f}, \mathrm{s}}{ }^{2}\left(\rho_{\mathrm{a}, \mathrm{f}}{ }^{2} x^{2}-\rho_{\mathrm{s}, \mathrm{a}}{ }^{2} x_{\mathrm{s}}{ }^{2}\right), b_{1}=2 \rho_{\mathrm{a}, \mathrm{f}} \rho_{\mathrm{f}, \mathrm{s}} \rho_{\mathrm{s}, \mathrm{a}} x\left[\rho_{\mathrm{s}, \mathrm{a}} x_{\mathrm{s}}{ }^{2} \cos \Delta_{2}-\rho_{\mathrm{s}, \mathrm{a}}{ }^{-1} \cos \Delta_{1}\right], \\
& c_{1}=2 \rho_{\mathrm{a}, \mathrm{f}} \rho_{\mathrm{f}, \mathrm{s}} \rho_{\mathrm{s}, \mathrm{a}} x\left[\rho_{\mathrm{s}, \mathrm{a}} x_{\mathrm{s}}{ }^{2} \sin \Delta_{2}-\rho_{\mathrm{s}, \mathrm{a}}{ }^{-1} \sin \Delta_{1}\right] \\
& \tau_{\mathrm{a}, \mathrm{f}} \tau_{\mathrm{f}, \mathrm{s}} \tau_{\mathrm{s}, \mathrm{a}}=\frac{8}{\sqrt{(n+1)^{2}+k^{2}}} \sqrt{\frac{n^{2}+k^{2}}{\left(n+n_{\mathrm{s}}\right)^{2}+\left(k+k_{\mathrm{s}}\right)^{2}}} \sqrt{\frac{n_{\mathrm{s}}{ }^{2}+k_{\mathrm{s}}{ }^{2}}{\left(n_{\mathrm{s}}+1\right)^{2}+k_{\mathrm{s}}{ }^{2}}}, \\
& \rho_{\mathrm{a}, \mathrm{f}}=\sqrt{\frac{(n-1)^{2}+k^{2}}{(n+1)^{2}+k^{2}}}, \rho_{\mathrm{f}, \mathrm{s}}=\sqrt{\frac{\left(n-n_{\mathrm{s}}\right)^{2}+\left(k-k_{\mathrm{s}}\right)^{2}}{\left(n+n_{\mathrm{s}}\right)^{2}+\left(k+k_{\mathrm{s}}\right)^{2}}}, \rho_{\mathrm{s}, \mathrm{a}}=\sqrt{\frac{\left(n_{\mathrm{s}}-1\right)^{2}+k_{\mathrm{s}}{ }^{2}}{\left(n_{\mathrm{s}}+1\right)^{2}+k_{\mathrm{s}}{ }^{2}}}, \\
& \Delta_{1}=\tan ^{-1}\left(\frac{2 k}{n^{2}+k^{2}-1}\right)+\pi+\tan ^{-1}\left[\frac{2\left(k n_{\mathrm{s}}-k_{\mathrm{s}} n\right)}{n^{2}-n_{\mathrm{s}}{ }^{2}+k^{2}-k_{\mathrm{s}}{ }^{2}}\right], \Delta_{2}=\tan ^{-1}\left(\frac{2 k}{n^{2}+k^{2}-1}\right)+\pi-\tan ^{-1}\left[\frac{2\left(k n_{\mathrm{s}}-k_{\mathrm{s}} n\right)}{n^{2}-n_{\mathrm{s}}{ }^{2}+k^{2}-k_{\mathrm{s}}{ }^{2}}\right]
\end{aligned}
$$

$T_{\mathrm{u}}(\lambda)$ represents the transmittance of an uniform film, $x(\lambda)$ is the absorbance of the film, the subscript 's' refers to the respective known substrate characteristics, and $n(\lambda)>n_{\mathrm{s}}(\lambda)>1$.

The formula providing most accurate approximation of the points $T_{+}\left(\lambda_{\mathrm{t}}\right)$ and $T_{-}\left(\lambda_{\mathrm{t}}\right)$ from the upper envelope and the lower envelope of $T_{\mathrm{sm}}(\lambda)$ is [11]:

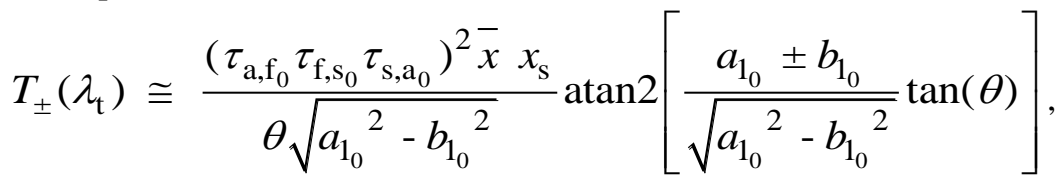

where ' $+{ }^{\prime}$ from the ' \pm ' signs refers to $T_{+}(\lambda)$, and ' - ' to $T_{-}(\lambda)$,

$$
\begin{aligned}
& \theta=2 \pi n \Delta \mathrm{d} / \lambda_{\mathrm{t}}, \bar{x}=\exp \left(-4 \pi k \overline{\mathrm{d}} / \lambda_{\mathrm{t}}\right), x_{\mathrm{s}}=\exp \left(-4 \pi k_{\mathrm{s}} \mathrm{d}_{\mathrm{s}} / \lambda_{\mathrm{t}}\right) \text {, } \\
& a_{\mathrm{1}_{0}}=1-\left(\rho_{\mathrm{a}, \mathrm{f}_{0}} \rho_{\mathrm{s}, \mathrm{a}_{0}} \bar{x} x_{\mathrm{s}}\right)^{2}+\rho_{\mathrm{f}, \mathrm{s}_{0}}{ }^{2}\left(\rho_{\mathrm{a}, \mathrm{f}_{0}}{ }^{2}{ }^{-2}-\rho_{\mathrm{s}, \mathrm{a}_{0}}{ }^{2} x_{\mathrm{s}}{ }^{2}\right), b_{\mathrm{1}_{0}}=2 \rho_{\mathrm{a}, \mathrm{f}_{0}} \rho_{\mathrm{f}, \mathrm{s}_{0}} \rho_{\mathrm{s}, \mathrm{a}_{0}} \bar{x}\left(\rho_{\mathrm{s}, \mathrm{a}_{0}}{ }^{-1}-\rho_{\mathrm{s}, \mathrm{a}_{0}} x_{\mathrm{s}}{ }^{2}\right) \text {, } \\
& \tau_{\mathrm{a}, \mathrm{f}_{0}}=\frac{2}{n+1}, \tau_{\mathrm{f}, \mathrm{s}_{0}}=\frac{2 n}{n+n_{\mathrm{s}}}, \tau_{\mathrm{s}, \mathrm{a}_{0}}=\frac{2 n_{\mathrm{s}}}{n_{\mathrm{s}}+1}, \quad \rho_{\mathrm{a}, \mathrm{f}_{0}}=\frac{n-1}{n+1}, \quad \rho_{\mathrm{f}, \mathrm{s}_{0}}=\frac{n-n_{\mathrm{s}}}{n+n_{\mathrm{s}}}, \quad \rho_{\mathrm{s}, \mathrm{a}_{0}}=\frac{n_{\mathrm{s}}-1}{n_{\mathrm{s}}+1} \text {. }
\end{aligned}
$$

The interference fringes equation is:

$$
2 n\left(\lambda_{\mathrm{t}}\right) \overline{\mathrm{d}} \cong m\left(\lambda_{\mathrm{t}}\right) \lambda_{\mathrm{t}}(\mathrm{i})\left\{\begin{array}{c}
m \geq 1-\text { integer for all tangency wavelengths } \lambda_{\mathrm{t}_{+}} \text {from the envelope } T_{+}(\lambda) \\
m \geq 1 / 2-\text { half - integer for all tangency wavelengths } \lambda_{\mathrm{t}_{-}} \text {from the envelope } T_{-}(\lambda)
\end{array}\right.
$$

where ' $i$ ' is a positive integer showing the number of the ' $\mathrm{i}$-th' extremum of $T_{\mathrm{sm}}(\lambda)$ counted from 1 closest from the higher wavelengths end, and $m\left[\lambda_{\mathrm{t}}(\mathrm{i})\right]$ is the interference order number of this extremum. 


\section{International Advanced Research Journal in Science, Engineering and Technology}

Vol. 7, Issue 3, March 2020

Eqs. (2,3) have been derived assuming $n^{2}(\lambda)>n_{\mathrm{s}}{ }^{2}(\lambda)>k^{2}(\lambda)$ and $n_{\mathrm{s}}{ }^{2}(\lambda)>k_{\mathrm{s}}{ }^{2}(\lambda)[10,11]$, as these relationships are commonly satisfied, in the UV/VIS/NIR spectral region, for a thin dielectric or semiconductor film with $\overline{\mathrm{d}}=[300,5000]$ nm on a glass substrate [2]. Besides, it follows from Eq. (3) that the average film thickness can be approximated as $[8,10,11]$ :

$d_{1}\left[\lambda_{\mathrm{t}}(\mathrm{i})\right]=\frac{\lambda_{\mathrm{t}}(\mathrm{i}) \lambda_{\mathrm{t}}(\mathrm{i}+1)}{4\left[\lambda_{\mathrm{t}}(\mathrm{i}) n(\mathrm{i}+1)-\lambda_{\mathrm{t}}(\mathrm{i}+1) n(\mathrm{i})\right]} \approx \overline{\mathrm{d}}$.

The main part from the OEM algorithm from [11] for characterization of a thin film on a glass substrate is shown in Fig. 2. The subscript ' $c$ ' in Fig. 2 and the rest of this paper represents final computed values by the OEM.

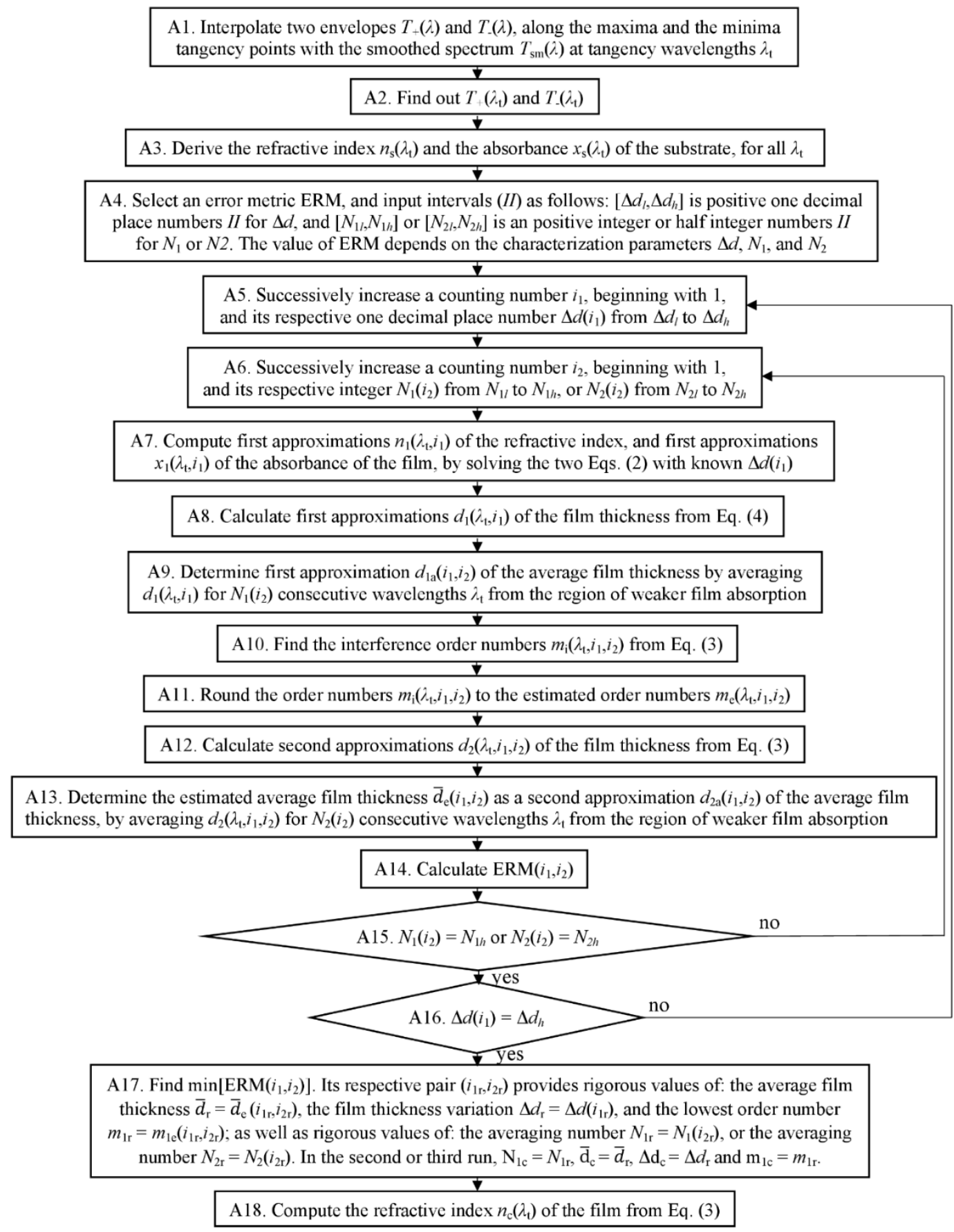

Figure 2. The main part from the OEM algorithm for computation of the average thickness $\overline{\mathrm{d}}$, the non-uniformity $\Delta \mathrm{d}$, and the refractive index $n\left(\lambda_{\mathrm{t}}\right)$ of the characterized thin film [11]. 


\section{International Advanced Research Journal in Science, Engineering and Technology}

Vol. 7, Issue 3, March 2020

Unlike the FEM and IEM, the OEM selects optimized values of $\overline{\mathrm{d}}$ and $\Delta \mathrm{d}$. In the OEM, this optimization is achieved by minimization of the value of error metric (ERM) related to the film thickness or the interference order numbers of the extrema in $T_{\mathrm{sm}}(\lambda)$. It has been demonstrated in [11] that the OEM provides more accurate film characterization compared to the FEM and IEM.

Besides, two rf magnetron sputtered a-Si thin films with dissimilar $\overline{\mathrm{d}}$ have been characterized in [18] by the OEM from [11], the optimizing graphical method [19], the Tauc-Lorentz-Urbach model method [20], and the Cody-Lorentz-Urbach model method [21]. These four characterization methods have been chosen as most likely to provide accurate characterization of the two a-Si films. A comparison of the obtained results has demonstrated that the OEM has rendered most accurate characterization of the two a-Si films, among these four characterization methods [18]. It has also been indicated in [18] that the OEM has a capacity for providing most accurate characterization of almost every dielectric or semiconductor film with $\overline{\mathrm{d}}=[300,5000] \mathrm{nm}$ on a glass substrate, compared to all existing methods for characterization of such films only from $T(\lambda)$.

Nevertheless, there is no systematic study regarding the selection of the error metric ERM used at step A14 of the OEM algorithm from Fig. 2. To resolve this problem, in this paper is investigated and compared the performance of seven ERM candidates. The study uses four model films, representing wide classes of thin dielectric and semiconductor films, their respective model specimens and normal incidence transmittance spectra $T(\lambda)$.

\section{An approach for selection of best ERM for the OEM}

To represent wide classes of thin films, four model specimens are considered, consisting of a model thin film on a 0.9 mm thick Corning7059 glass substrate with known $n_{\mathrm{s}}(\lambda)$ and $k_{\mathrm{s}}(\lambda)$ [11]. Each of the four model films has a refractive index $n(\lambda[\mathrm{nm}])=3 \times 10^{5} / \lambda^{2}+2.6$, an average thickness of $\overline{\mathrm{d}}=1000 \mathrm{~nm}$, and $k_{0}(\lambda[\mathrm{nm}])=$ $[\lambda /(4 \pi)] \cdot 10^{\left(1.5 \times 10^{6} / \lambda^{2}\right)-8}$ is used for introduction of the extinction coefficient of the film. These $n(\lambda)$ and $k_{0}(\lambda)$ are typical values for a-Si:H film [8]. The extinction coefficient and the thickness non-uniformity of the model film, from each of the model specimens 1 to 4 , are:

Model film 1: $k(\lambda)=k_{0}(\lambda)$ and $\Delta \mathrm{d}=3 \mathrm{~nm}$. These characteristics represent a class of quasi-uniform films with a wide spectral region of quasi-transparency.

Model film 2: $k(\lambda)=k_{0}(\lambda)$ and $\Delta \mathrm{d}=30 \mathrm{~nm}$. These data represent a class of non-uniform films with a wide quasitransparency region.

Model film 3: $k(\lambda)=k_{0}(\lambda)+0.01$ and $\Delta \mathrm{d}=3 \mathrm{~nm}$. These data represent a class of quasi-uniform films without a quasitransparency region.

Model film 4: $k(\lambda)=k_{0}(\lambda)+0.01$ and $\Delta \mathrm{d}=30 \mathrm{~nm}$. These data represent a class of non-uniform films without a quasitransparency region.
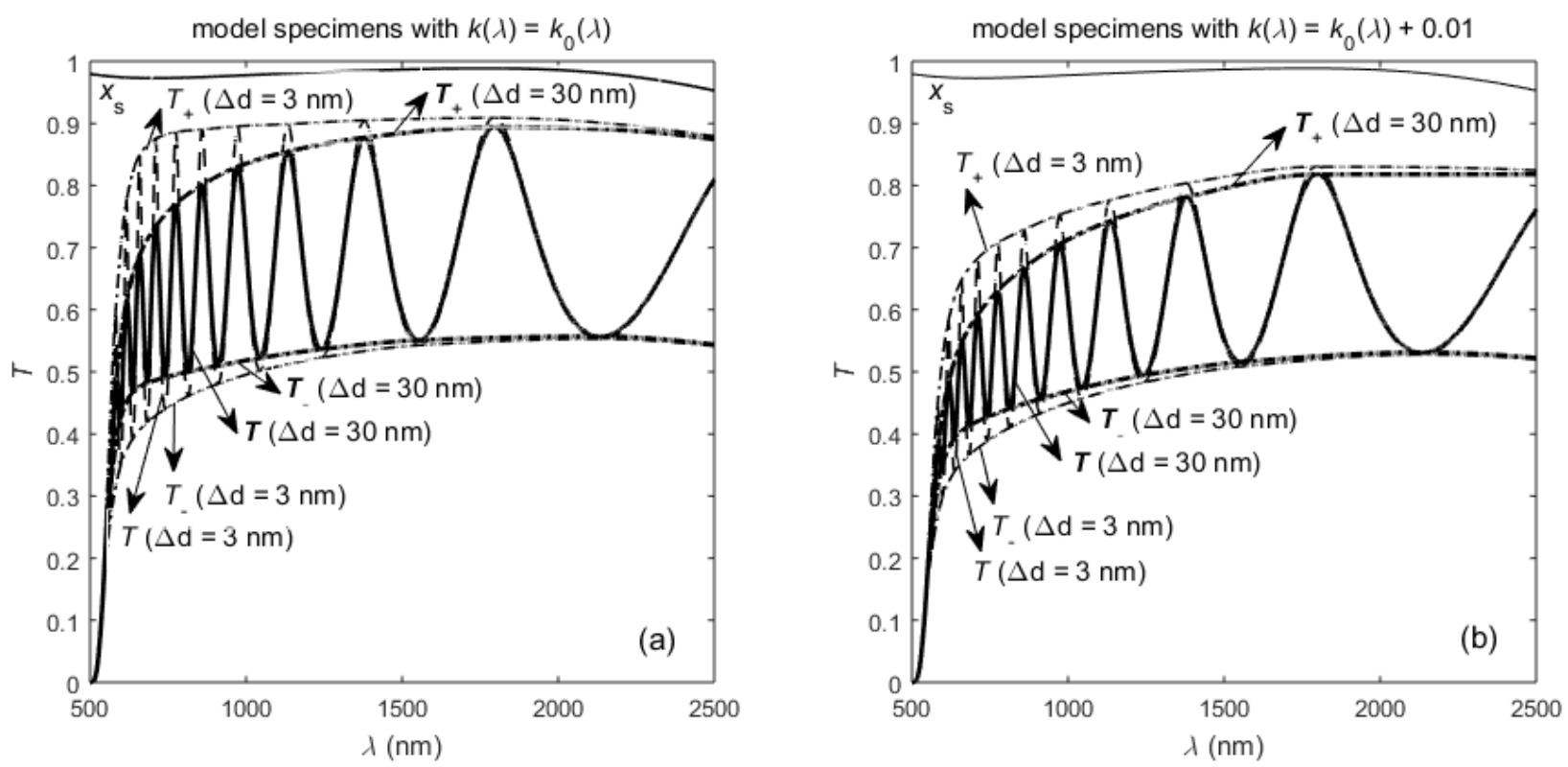

Figure 3. Simulated transmittance spectrum $T(\lambda)$ with envelopes $T_{+}(\lambda)$ and $T_{-}(\lambda)$ for the four model specimens, and the substrate absorbance $x_{\mathrm{s}}(\lambda)$. (a) for the specimens 1 and 2, as the film has a wide quasi-transparency region. (b) for the specimens 3 and 4, as the film does not have a quasi-transparency region. 


\section{International Advanced Research Journal in Science, Engineering and Technology}

Vol. 7, Issue 3, March 2020

The transmittance spectrum $T(\lambda)$ is simulated by adding $0.1 \%$ white noise to transmittance spectrum $T_{0}(\lambda)$, obtained from Eq. (1), for each of the model specimens. Such noise is typical for measurement of the transmittance through a high refractive index material [22]. The envelopes $T_{+}(\lambda)$ and $T_{-}(\lambda)$ of $T_{\mathrm{sm}}(\lambda)$ are computed by using the algorithm from [23], accounting for the substrate absorption. $T(\lambda), T_{+}(\lambda)$ and $T_{-}(\lambda)$ of the four model specimens are shown in Fig. 3.

It is seen from Fig. 3 that the interference pattern of $T(\lambda)$ has different appearance for the four model specimens. Correspondingly, it is possible to classify a particular film into one of the four film classes, represented by the model films 1 to 4 , only by observation of the appearance of the interference pattern of $T(\lambda)$.

During a particular OEM characterization of a model film, from its respective $T(\lambda)$, each one of the following ERMs would be employed at step A14 of the OEM algorithm:

$$
\begin{aligned}
& \operatorname{RE}\left(d_{1 \mathrm{a}}, d_{2 \mathrm{a}}\right)=\frac{d_{1 \mathrm{a}}-d_{2 \mathrm{a}}}{d_{2 \mathrm{a}}} \\
& \operatorname{RMSE}\left(m_{\mathrm{i}}, m_{\mathrm{e}}\right)=\sqrt{\frac{\sum_{\mathrm{i}=1}^{N_{2}}\left\{m_{\mathrm{i}}\left[\lambda_{\mathrm{t}}(\mathrm{i})\right]-m_{\mathrm{e}}\left[\lambda_{\mathrm{t}}(\mathrm{i})\right]\right\}^{2}}{N_{2}}} \\
& \frac{\operatorname{RMSE}\left(m_{\mathrm{i}}, m_{\mathrm{e}}\right)}{N_{2}} \\
& S D\left(d_{2}, d_{2 \mathrm{a}}\right)=\sqrt{\frac{\sum_{\mathrm{i}=1}^{N_{2}}\left\{d_{2}\left[\lambda_{\mathrm{t}}(\mathrm{i})\right]-d_{2 \mathrm{a}}\right\}^{2}}{N_{2}}} \\
& \frac{S D\left(d_{2}, d_{2 \mathrm{a}}\right)}{N_{2}} \\
& \operatorname{TRRSE}_{+}\left(m_{\mathrm{i}}, m_{\mathrm{e}}, d_{2}, d_{2 \mathrm{a}}\right)=\sqrt{\frac{\sum_{\mathrm{i}=1}^{N_{2}}\left\{m_{\mathrm{i}}\left[\lambda_{\mathrm{t}}(\mathrm{i})\right]-m_{\mathrm{e}}\left[\lambda_{\mathrm{t}}(\mathrm{i})\right]\right\}^{2}}{N_{2} m_{\mathrm{ia}}{ }^{2}}+\frac{\sum_{\mathrm{i}=1}^{N_{2}}\left\{d_{2}\left[\lambda_{\mathrm{t}}(\mathrm{i})\right]-d_{2 \mathrm{a}}\right\}^{2}}{N_{2} d_{2 \mathrm{a}}{ }^{2}}} \\
& \operatorname{TRRSE}_{-}\left(m_{\mathrm{i}}, m_{\mathrm{e}}, d_{2}, d_{2 \mathrm{a}}\right)=\sqrt{\frac{\sum_{\mathrm{i}=1}^{N_{2}}\left\{m_{\mathrm{i}}\left[\lambda_{\mathrm{t}}(\mathrm{i})\right]-m_{\mathrm{e}}\left[\lambda_{\mathrm{t}}(\mathrm{i})\right]\right\}^{2}}{N_{2} m_{\mathrm{ia}}{ }^{2}}-\frac{\sum_{\mathrm{i}=1}^{N_{2}}\left\{d_{2}\left[\lambda_{\mathrm{t}}(\mathrm{i})\right]-d_{2 \mathrm{a}}\right\}^{2}}{N_{2} d_{2 \mathrm{a}}{ }^{2}}} \text { with ERM number } \mathrm{j}=7 \text {. }
\end{aligned}
$$

In Eq. (5), the subscript ' $a$ ' represents an averaged value, $m_{\mathrm{ia}}=\left(\sum_{\mathrm{i}=1}^{N_{2}} m_{\mathrm{i}}\left[\lambda_{\mathrm{t}}(\mathrm{i})\right]\right) / N_{2}$, the symbol ' $R E$ ' means relative error, ' $R M S E$ ' - root mean square error, ' $S D$ ' - standard deviation, and 'TRRSE' - total relative root square error. ERM number $\mathrm{j}$ from 1 to 7 is ascribed to each of the ERMs from Eq. (5).

The execution of the steps A1 to A17 from the OEM algorithm provides computed values $\overline{\mathrm{d}}_{\mathrm{c}}, \Delta \mathrm{d}_{\mathrm{c}}$, and $\mathrm{m}_{1 \mathrm{c}}$ of their respective true values $\overline{\mathrm{d}}, \Delta \mathrm{d}$, and $m_{1}$; by finding the global minimum of a particular ERM using all credible sets $\left(\Delta d, N_{1}, N_{2}\right)$. Therefore, seven different sets of $\overline{\mathrm{d}}_{\mathrm{c}}, \Delta \mathrm{d}_{\mathrm{c}}, \mathrm{m}_{1 \mathrm{c}}$ corresponding to each one of the seven ERMs from Eq. (5) can be computed in just one film characterization by the OEM algorithm.

The computed values $n_{\mathrm{c}}\left(\lambda_{\mathrm{t}}\right)$ of $n\left(\lambda_{\mathrm{t}}\right)$ are obtained, from Eq. (3) at step A18 from the OEM algorithm, by substituting $\overline{\mathrm{d}}_{\mathrm{c}}$ as the average film thickness and $\mathrm{m}_{\mathrm{c}}\left(\lambda_{\mathrm{t}}\right)$ as the integer or half-integer order numbers. Besides, the computed values $k_{\mathrm{c}}\left(\lambda_{\mathrm{t}}\right)$ of $k\left(\lambda_{\mathrm{t}}\right)$ can be determined by solving Eq. (1) or Eq.(2), employing $\overline{\mathrm{d}}_{\mathrm{c}}, \Delta \mathrm{d}_{\mathrm{c}}$, and $n_{\mathrm{c}}\left(\lambda_{\mathrm{t}}\right)$ [11].

Furthermore, a smaller deviation of $\bar{d}_{c}$ from $\bar{d}$, and/or of $\Delta \mathrm{d}_{\mathrm{c}}$ from $\Delta \mathrm{d}$ corresponds to more accurate characterization of the film. In this regard, the following figures of merit (FOM) can represent the standard deviations of $\overline{\mathrm{d}}_{\mathrm{c}}$ from $\overline{\mathrm{d}}$, and/or of $\Delta \mathrm{d}_{\mathrm{c}}$ from $\Delta \mathrm{d}$ : 
Vol. 7, Issue 3, March 2020

$\mathrm{SD}\left(\overline{\mathrm{d}}_{\mathrm{c}}, \overline{\mathrm{d}}\right)=\sqrt{\frac{\sum_{\mathrm{i}=1}^{\mathrm{N}}\left[\overline{\mathrm{d}}_{\mathrm{c}}(\mathrm{i})-\overline{\mathrm{d}}\right]^{2}}{\mathrm{~N}}} \geq 0, \quad \mathrm{SD}\left(\Delta \mathrm{d}_{\mathrm{c}}, \Delta \mathrm{d}\right)=\sqrt{\frac{\sum_{\mathrm{i}=1}^{\mathrm{N}}\left[\Delta \mathrm{d}_{\mathrm{c}}(\mathrm{i})-\Delta \mathrm{d}(\mathrm{i})\right]^{2}}{\mathrm{~N}}} \geq 0$,

$\operatorname{TSD}\left(\overline{\mathrm{d}}_{\mathrm{c}}, \overline{\mathrm{d}}_{,} \Delta \mathrm{d}_{\mathrm{c}}, \Delta \mathrm{d}\right)=\sqrt{\frac{\sum_{\mathrm{i}=1}^{\mathrm{N}}\left\{\left[\overline{\mathrm{d}}_{\mathrm{c}}(\mathrm{i})-\overline{\mathrm{d}}\right]^{2}+\left[\Delta \mathrm{d}_{\mathrm{c}}(\mathrm{i})-\Delta \mathrm{d}(\mathrm{i})\right]^{2}\right\}}{\mathrm{N}}} \geq 0$,

$\operatorname{RMSD}\left(\overline{\mathrm{d}}_{\mathrm{cj}}, \overline{\mathrm{d}}_{\mathrm{c} 5}\right)=\sqrt{\frac{\sum_{\mathrm{i}=1}^{\mathrm{N}}\left[\overline{\mathrm{d}}_{\mathrm{cj}}(\mathrm{i})-\overline{\mathrm{d}}_{\mathrm{c} 5}(\mathrm{i})\right]^{2}}{\mathrm{~N}}} \geq 0$

for a variable number $\mathrm{N}$ of film characterizations by the OEM, each of them using one of the ERMs from Eq. (5). In Eq. (6), 'TSD' means total standard deviation, and the root mean square deviation 'RMSD' represents the averaged deviation of $\overline{\mathrm{d}}_{\mathrm{c}}$ for the ERM with number $\mathrm{j}$ from the respective $\overline{\mathrm{d}}_{\mathrm{c}}$ for the ERM with number 5, i.e. for $S D\left(d_{2}, d_{2 \mathrm{a}}\right) / N_{2}$. Therefore, the ERM from Eq. (5) rendering smallest values of FOMs from Eq. (6) can be selected as best ERM for accurate film characterizations by the OEM.

\section{II.COMPUTED RESULTS}

With respect to the third paragraph from Section two, one of two different $0.1 \%$ white noises with spectra $W N_{1}(\lambda)$ and $W N_{2}(\lambda)$ is added to $T_{0}(\lambda)$ from Eq. (1), thus providing two slightly different $T(\lambda)$ for each model specimen, to account for possible influence of the white noise on the computed film characteristics. Furthermore, erroneous determination of some tangency wavelengths $\lambda_{\mathrm{t}}(\mathrm{i})$ causes inaccuracy in the film characterization by any version of the EM [8,10,11]. To assess such inaccuracy, an independent OEM characterization is performed by employing the wavelengths $\lambda_{\text {extr }}(i)$ of the extrema of the smoothed interference pattern, instead of $\lambda_{\mathrm{t}}(\mathrm{i})$, for every $T(\lambda)$.

Sixteen computed pairs $\left(\Delta \mathrm{d}_{\mathrm{c}}, \overline{\mathrm{d}}_{\mathrm{c}}\right)\left(4\right.$ model specimens $\times 2$ white noises $\times 2$ wavelength sets $\lambda_{\mathrm{t}}$ and $\left.\lambda_{\text {extr }}\right)$ were derived from the OEM characterizations, for each of the seven ERMs from Eq. (5). These computed data are used for calculation of the four FOMs from Eq. (6). Such FOMs data are presented in grouped bar charts, as each chart includes seven ERM number groups representing the seven ERMs with numbers introduced in Eq. (5).

Two grouped bar charts for $\mathrm{SD}\left(\Delta \mathrm{d}_{\mathrm{c}}, \Delta \mathrm{d}\right)$ are shown in Fig. 4. The height of each of the rectangles from Fig. 4 represents $\mathrm{SD}\left(\Delta \mathrm{d}_{\mathrm{c}}, \Delta \mathrm{d}\right)$ calculated from Eq. (6) for $\mathrm{N}=2$ data of $\Delta \mathrm{d}_{\mathrm{c}}$ computed for $W N_{1}(\lambda)$ and $W N_{2}(\lambda)$, respectively.
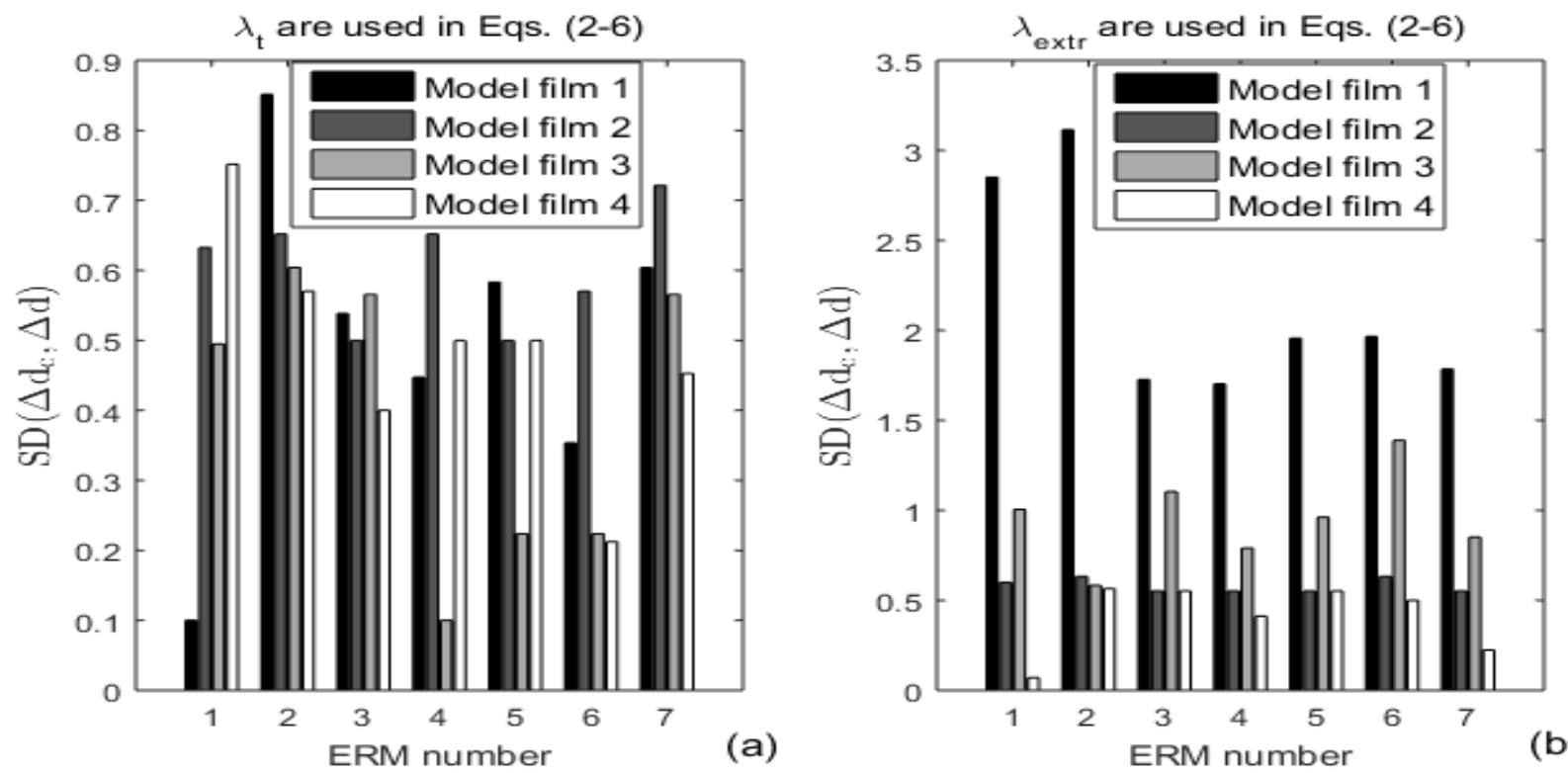

Figure 4. Grouped bar charts for $\operatorname{SD}\left(\Delta \mathrm{d}_{\mathrm{c}}, \Delta \mathrm{d}\right)$. The four differently coloured rectangles corresponding to a given ERM number group refer to the four model films. a) for the wavelengths set $\lambda_{t}(i)$. b) for the wavelengths set $\lambda_{\text {extr }}(i)$. 


\section{International Advanced Research Journal in Science, Engineering and Technology}

Vol. 7, Issue 3, March 2020

To investigate the influence of the different ERMs on the accuracy of computation of the average film thickness, two grouped bar charts for $\operatorname{SD}\left(\overline{\mathrm{d}}_{\mathrm{c}}, \overline{\mathrm{d}}\right)$ are exhibited in Fig. 5. The height of each of the rectangles from Fig. 5 represents $\operatorname{SD}\left(\overline{\mathrm{d}}_{\mathrm{c}}, \overline{\mathrm{d}}\right)$, derived from Eq. (6), for $\mathrm{N}=2$ data of $\overline{\mathrm{d}}_{\mathrm{c}}$ computed for $W N_{1}(\lambda)$ and $W N_{2}(\lambda)$.
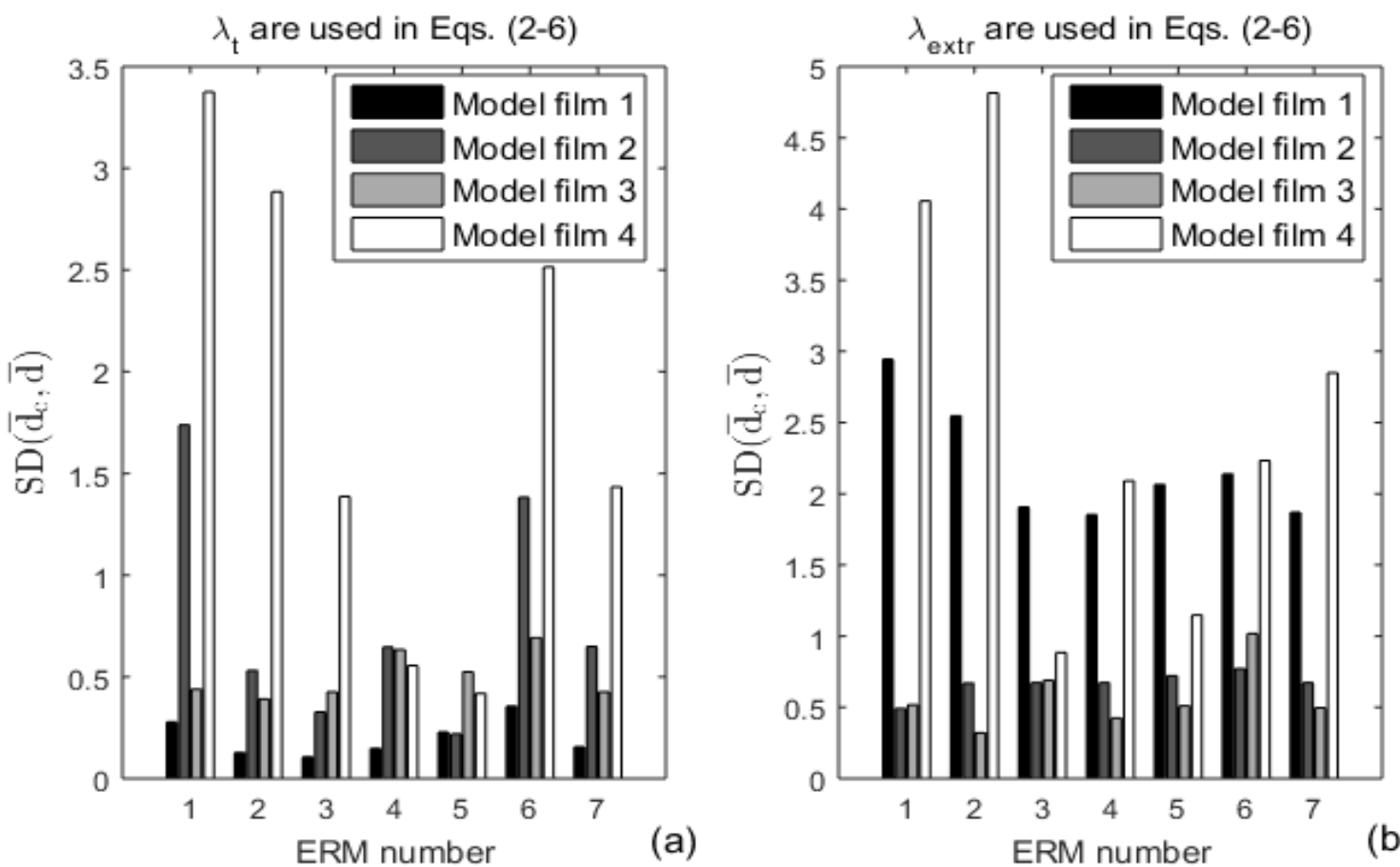

Figure 5. Grouped bar charts for $\operatorname{SD}\left(\overline{\mathrm{d}}_{\mathrm{c}}, \overline{\mathrm{d}}\right)$. The four differently coloured rectangles corresponding to a given ERM number group refer to the four model films. a) for the wavelengths set $\lambda_{t}(i)$. b) for the wavelengths set $\lambda_{\text {extr }}(i)$.

Fig 6 consists of two grouped bar charts for $\operatorname{TSD}\left(\Delta \mathrm{d}_{c}, \Delta \mathrm{d}, \overline{\mathrm{d}}_{\mathrm{c}}, \overline{\mathrm{d}}\right)$. The height of each of the rectangles from Fig. 5 represents $\operatorname{TSD}\left(\Delta \mathrm{d}_{c}, \Delta \mathrm{d}, \overline{\mathrm{d}}_{c}, \overline{\mathrm{d}}\right)$, from Eq. (6), for $\mathrm{N}=2$ pairs $\left(\Delta \mathrm{d}_{c}, \overline{\mathrm{d}}_{\mathrm{c}}\right)$ obtained for $W N_{1}(\lambda)$ and $W N_{2}(\lambda)$, respectively.
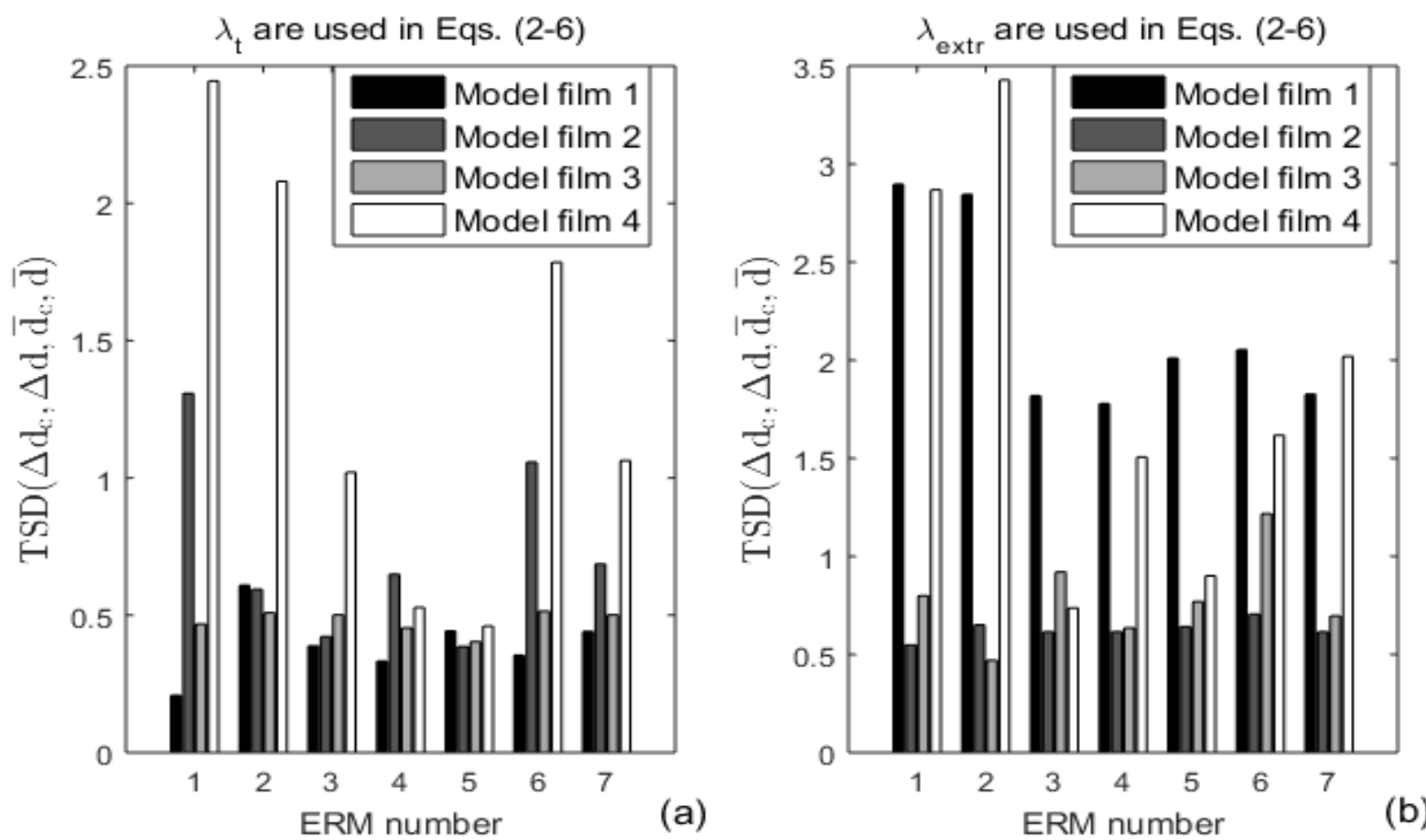

Figure 6. Grouped bar charts for $\operatorname{TSD}\left(\Delta \mathrm{d}_{c}, \Delta \mathrm{d}, \overline{\mathrm{d}}_{\mathrm{c}}, \overline{\mathrm{d}}\right)$. The four differently coloured rectangles of a given ERM number group correspond to the four model films. a) for the wavelengths set $\lambda_{t}(i)$. b) for the wavelengths set $\lambda_{\text {extr }}(i)$. 


\section{International Advanced Research Journal in Science, Engineering and Technology}

Vol. 7, Issue 3, March 2020

Another two grouped bar charts for $\operatorname{SD}\left(\overline{\mathrm{d}}_{\mathrm{c}}, \overline{\mathrm{d}}\right)$ are shown in Fig. 7. The height of each of the rectangles from Fig. 7 represents $\operatorname{SD}\left(\overline{\mathrm{d}}_{\mathrm{c}}, \overline{\mathrm{d}}\right)$ for $\mathrm{N}=4$ data of $\overline{\mathrm{d}}_{\mathrm{c}}$ computed for the four model films.
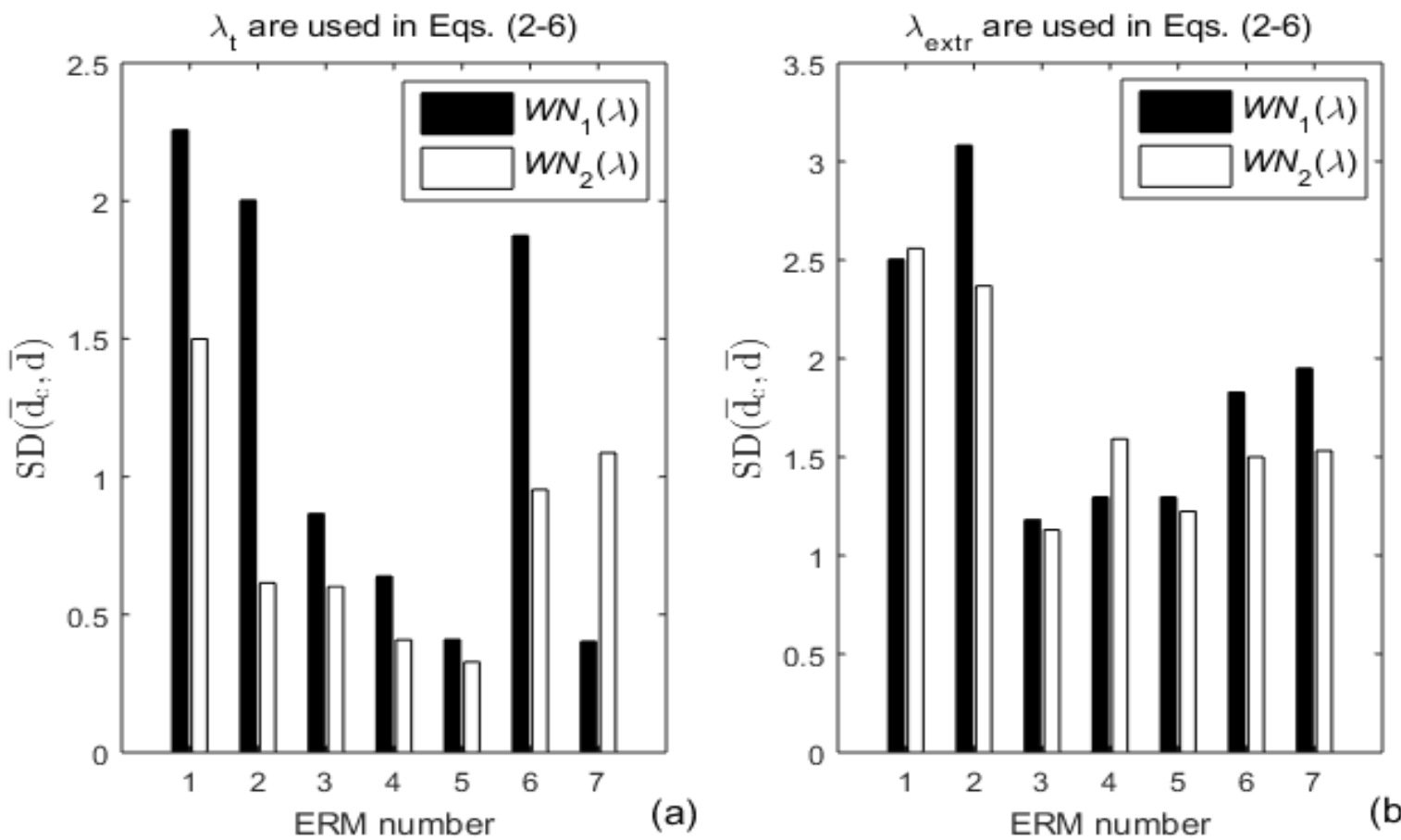

Figure 7. Grouped bar charts for $\operatorname{SD}\left(\overline{\mathrm{d}}_{\mathrm{c}}, \overline{\mathrm{d}}\right)$. The two differently coloured rectangles corresponding to a given ERM number group refer to the white noises with spectra $W N_{1}(\lambda)$ and $W N_{2}(\lambda)$. a) for the wavelengths set $\lambda_{t}(\mathrm{i})$. b) for the wavelengths set $\lambda_{\text {extr }}(\mathrm{i})$.

Grouped bar charts for $\operatorname{SD}\left(\Delta \mathrm{d}_{c}, \Delta \mathrm{d}\right)$ and $\operatorname{SD}\left(\overline{\mathrm{d}}_{\mathrm{c}}, \overline{\mathrm{d}}\right)$ are also presented in Fig. 8 for understanding the influence of the different ERMs on the accuracy of computation of each one of $\Delta \mathrm{d}_{\mathrm{c}}$ and $\overline{\mathrm{d}}_{\mathrm{c}}$, disregarding the optical characteristics of the thin film. The height of each of the rectangles from Fig. 8 represents FOM for $\mathrm{N}=16$ data of $\Delta \mathrm{d}_{\mathrm{c}}$ or $\overline{\mathrm{d}}_{\mathrm{c}}$, computed for the four model films combined with the two $0.1 \%$ white noise spectra $W N_{1}(\lambda)$ and $W N_{2}(\lambda)$, and the two wavelength sets $\lambda_{t}$ and $\lambda_{\text {extr. }}$.
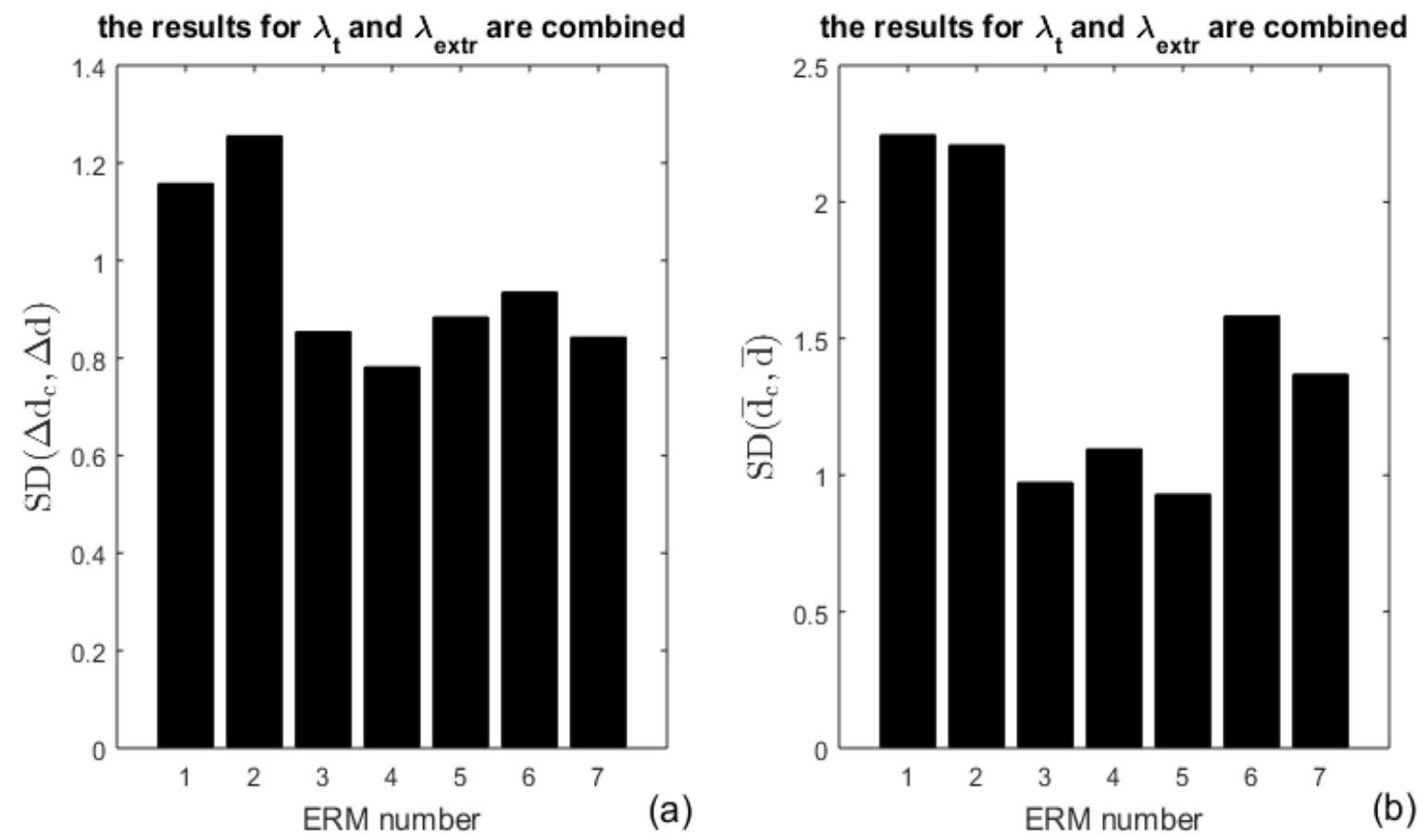


\section{International Advanced Research Journal in Science, Engineering and Technology}

Vol. 7, Issue 3, March 2020

Figure 8. a) Grouped bar charts for $\operatorname{SD}\left(\Delta \mathrm{d}_{\mathrm{c}}, \Delta \mathrm{d}\right)$. b) Grouped bar chart for $\operatorname{SD}\left(\overline{\mathrm{d}}_{\mathrm{c}}, \overline{\mathrm{d}}\right)$. Each rectangle corresponding to a given ERM number group refers to the four model films combined with the white noise spectra $W N_{1}(\lambda)$ and $W N_{2}(\lambda)$, and the wavelength sets $\lambda_{\mathrm{t}}$ and $\lambda_{\text {extr. }}$

Two bar charts RMSD $\left(\overline{\mathrm{d}}_{\mathrm{c} j}, \overline{\mathrm{d}}_{\mathrm{c} 5}\right)$ are shown in Fig. 9. The height of each of the rectangles from Fig. 9 represents $\operatorname{RMSD}\left(\overline{\mathrm{d}}_{\mathrm{cj}}, \overline{\mathrm{d}}_{\mathrm{c}}\right)$, calculated from Eq. (6), for $\mathrm{N}=2$ pairs $\left(\overline{\mathrm{d}}_{\mathrm{cj}}, \overline{\mathrm{d}}_{\mathrm{c}}\right)$ computed for $W N_{1}(\lambda)$ and $W N_{2}(\lambda)$, respectively.
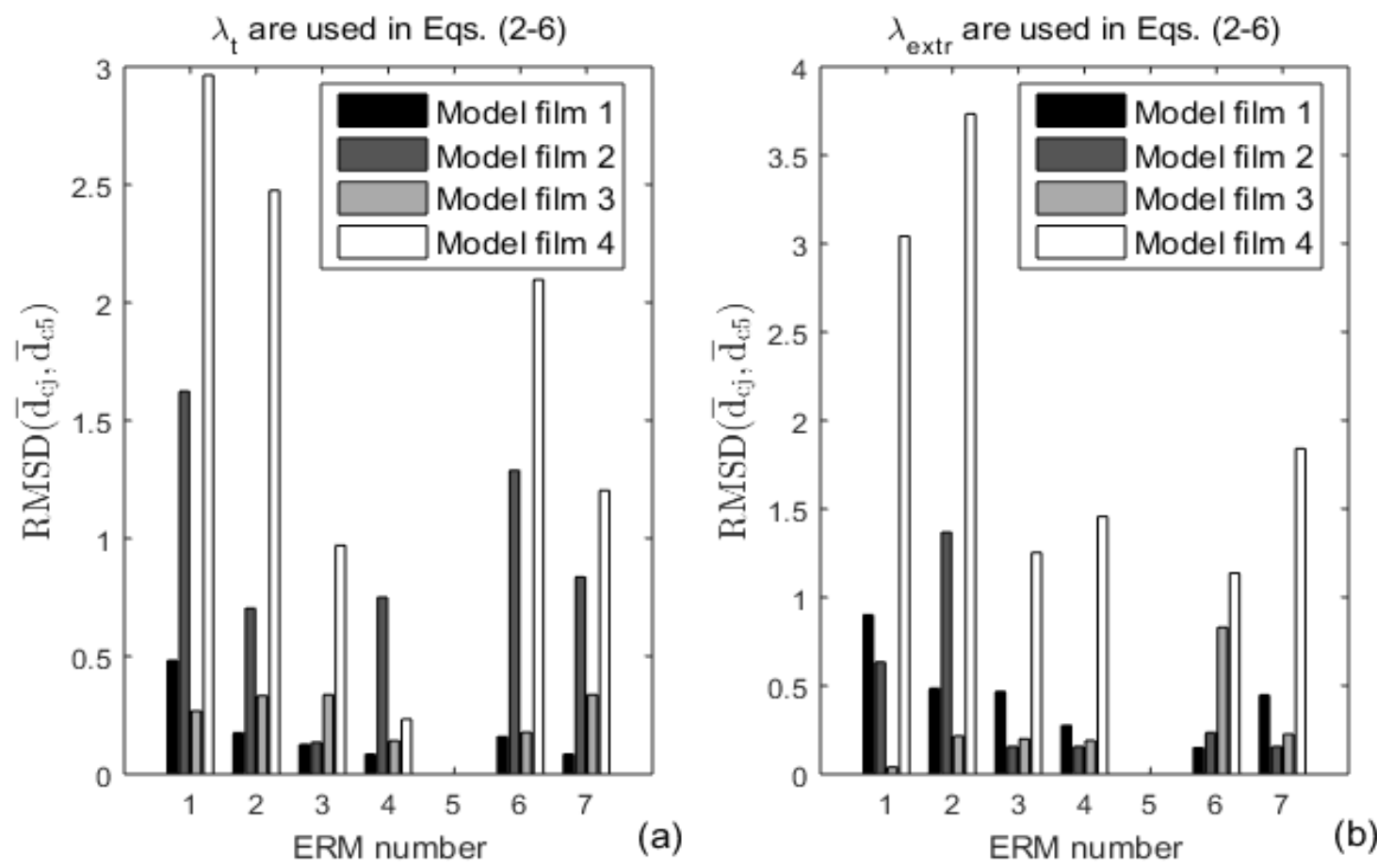

Figure 9. Grouped bar charts for RMSD $\left(\overline{\mathrm{d}}_{\mathrm{cj}}, \overline{\mathrm{d}}_{\mathrm{c} 5}\right)$. The four differently coloured rectangles of a given ERM number group correspond to the four model films. a) for the wavelengths set $\lambda_{t}(i)$. b) for the wavelengths set $\lambda_{\text {extr }}(i)$.

\section{III.DISCUSSION}

A common feature of all EMs is that they compute the thickness characteristics of the film first, followed by computation of its $n(\lambda)$, as $k(\lambda)$ is computed last [8,10,11]. Therefore, accurate computation of $\Delta \mathrm{d}$ and $\overline{\mathrm{d}}$ is needed for accurate computation of both $n(\lambda)$ and $k(\lambda)$ of a film characterized by the OEM. Besides, more accurate OEM characterization of $\Delta \mathrm{d}$ and $\overline{\mathrm{d}}$ of a film is represented by smaller FOMs from Eq. (6), which is also used for the preparation of the grouped bar charts from Figs. 4-9. Therefore, an analysis of these grouped bar charts can be employed for selection of ERM, to be used at step A14 of the OEM algorithm from Fig. 2, for increasing the accuracy of film characterization by the OEM. Correspondingly, ERM providing more accurate computed film thickness non-uniformity $\Delta \mathrm{d}_{\mathrm{c}}$ corresponds to a smaller rectangle, with the colour representing the film class, in the grouped bar chart for $\operatorname{SD}\left(\Delta \mathrm{d}_{\mathrm{c}}, \Delta \mathrm{d}\right)$ from Fig.4. Similarly, ERM providing more accurate computed average film thickness $\overline{\mathrm{d}}$ corresponds to a smaller rectangle, with the colour representing the film class, in the grouped bar chart for $\operatorname{SD}\left(\overline{\mathrm{d}}_{\mathrm{c}}, \overline{\mathrm{d}}\right)$ from Fig.5.

Furthermore, studying grouped bar charts from Section 3 allows drawing conclusions about the influence of factors related to the computation of the envelopes $T_{+}(\lambda)$ and $T_{-}(\lambda)$ of $T_{\mathrm{sm}}(\lambda)$ on the accuracy of film characterization by the OEM. In this respect, a comparison of a chart (a) with its respective chart (b) from Figs. 4, 5, 6, 8 shows that computing the envelopes using the set $\lambda_{t}$ leads to significantly more accurate OEM characterization than using the set $\lambda_{\text {extr. }}$ This result is in accordance with similar results for the other EMs $[8,10]$ indicating that $T_{+}(\lambda)$ and $T_{-}(\lambda)$ should be computed to touch the smoothed spectrum $T_{\mathrm{sm}}(\lambda)$ at its tangency wavelengths $\lambda_{\mathrm{t}}(\mathrm{i})$ rather than at its extrema wavelengths $\lambda_{\text {extr }}(\mathrm{i})$. In this respect, the use of the set $\lambda_{\text {extr }}$ in this study is regarded as representing erroneous computation of the envelopes of $T_{\mathrm{sm}}(\lambda)$. It is therefore concluded from the bar charts for $\operatorname{SD}\left(\Delta \mathrm{d}_{\mathrm{c}}, \Delta \mathrm{d}\right)$ from Figs 4 and $8 \mathrm{a}$ that relatively accurate computed thickness non-uniformity $\Delta \mathrm{d}_{\mathrm{c}}$ can be obtained by using the ERMs with numbers 3 , 4 , and 5 ; i.e. $R M S E\left(m_{\mathrm{i}}, m_{\mathrm{e}}\right) / N_{2}$, $S D\left(d_{2}, d_{2 \mathrm{a}}\right)$, and $S D\left(\mathrm{~d}_{2}, d_{2 \mathrm{a}}\right) / N_{2}$. Besides, a comparison of the data from Figs. $4 \mathrm{a}$ and $4 \mathrm{~b}$ indicate that largest inaccuracies 


\section{International Advanced Research Journal in Science, Engineering and Technology}

Vol. 7, Issue 3, March 2020

of $\Delta \mathrm{d}_{\mathrm{c}}$, due to erroneous computation of the envelopes, occur for the model specimen 1 representing non-uniform films with a wide region of quasi-transparency. It is also established from Figs. $4 \mathrm{a}$ and $4 \mathrm{~b}$ that most accurate $\Delta \mathrm{d}_{\mathrm{c}}$ of quasiuniform films without a quasi-transparency region is computed by using the ERM with number 4 , i.e. $S D\left(d_{2}, d_{2 \mathrm{a}}\right)$.

Moreover, the bar charts for $\operatorname{SD}\left(\overline{\mathrm{d}}_{\mathrm{c}}, \overline{\mathrm{d}}\right)$ from Figs 5 and 8b show that most accurate computed average film thickness $\overline{\mathrm{d}}_{\mathrm{c}}$ should be obtained by using $R M S E\left(m_{\mathrm{i}}, m_{\mathrm{e}}\right) / N_{2}, S D\left(d_{2}, d_{2 \mathrm{a}}\right)$, or $S D\left(\mathrm{~d}_{2}, d_{2 \mathrm{a}}\right) / N_{2}$ at step A41 of the OEM. Besides, the data from Fig. $5 b$ demonstrate that significant inaccuracy of $\overline{\mathrm{d}}_{\mathrm{c}}$ occur for quasi-uniform films with quasi-transparency region as a result of erroneous computation of the envelopes. However, the accuracy of $\overline{\mathrm{d}}_{\mathrm{c}}$ should be very high when both $S D\left(\mathrm{~d}_{2}, d_{2 \mathrm{a}}\right) / N_{2}$ is used in the OEM and the envelopes are computed precisely, according to data from Fig. 5a, independently from the class of the film.

Importantly, $n(\lambda)$ is computed by using Eq. (3), which contains $\overline{\mathrm{d}}$ and does not contain $\Delta \mathrm{d}$, in all EMs accounting for the non-uniformity of the film including the OEM [10,11]. Therefore, accurate $n_{c}\left(\lambda_{t}\right)$ requires accurate $\overline{\mathrm{d}}_{\mathrm{c}}$, and does not require explicitly accurate $\Delta \mathrm{d}_{c}$. In this regard, the bar charts from Fig. 9 are compiled taking into account the need for accurate $\overline{\mathrm{d}}_{\mathrm{c}}$ in order to compute accurately $n(\lambda)$ and $k(\lambda)$, as well as the provision of accurate $\overline{\mathrm{d}}_{\mathrm{c}}$ by using $S D\left(\mathrm{~d}_{2}, d_{2 \mathrm{a}}\right) / N_{2}$ in the OEM, independently from the class of the film. The data from Fig. 9 indicate that an accurate film characterization should lead to close to each other $\overline{\mathrm{d}}_{\mathrm{c}}$ computed by using $S D\left(\mathrm{~d}_{2}, d_{2 \mathrm{a}}\right) / N_{2}$ and $\operatorname{RMSE}\left(m_{\mathrm{i}}, m_{\mathrm{e}}\right) / N_{2}$ in the OEM, for all film classes except for non-uniform films without quasi-transparency region, when the envelopes are accurate. It is also seen from Fig. 9 that an accurate characterization should lead to close to each other $\overline{\mathrm{d}}_{\mathrm{c}}$ computed by using $S D\left(\mathrm{~d}_{2}, d_{2 \mathrm{a}}\right) / N_{2}$ and $S D\left(\mathrm{~d}_{2}, d_{2 \mathrm{a}}\right)$ in the OEM, for all film classes except for non-uniform films with quasi-transparency region, when the envelopes are accurate.

With respect to the typical $0.1 \%$ white noise in $T(\lambda)$, the bar charts from Fig. 7 indicate that the spectrum of this noise does not influence notably the accuracy of computation of $\overline{\mathrm{d}}_{\mathrm{c}}$ for any of the error metrics $\operatorname{RMSE}\left(m_{\mathrm{i}}, m_{\mathrm{e}}\right) / N_{2}, S D\left(d_{2}, d_{2 \mathrm{a}}\right)$, and $S D\left(\mathrm{~d}_{2}, d_{2 \mathrm{a}}\right) / N_{2}$ used in the OEM.

Notably, accurate computation of $k(\lambda)$ in the OEM requires accurate computation of both $\overline{\mathrm{d}}$ and $\Delta \mathrm{d}$. However, most accurate values of $\overline{\mathrm{d}}_{\mathrm{c}}$ and $\Delta \mathrm{d}_{\mathrm{c}}$ might be computed by using two different ERMs chosen amongst $R M S E\left(m_{\mathrm{i}}, m_{\mathrm{e}}\right) / N_{2}$, $S D\left(d_{2}, d_{2 \mathrm{a}}\right)$, and $S D\left(\mathrm{~d}_{2}, d_{2 \mathrm{a}}\right) / N_{2}$. For a given specimen, the selection of these two ERMs should be based on using the grouped bar charts from Figs. 4-9 and the above discussions; taking into account the appearance of $T(\lambda)$, determined by the class of the film, and the quality of the envelopes of $T(\lambda)$.

\section{IV.CONCLUSIONS}

An approach is presented for selection of the error metric ERM in the optimizing envelope method for characterization of a thin film on a glass substrate specimen only from its normal incidence interference transmittance spectrum $T(\lambda)$. The selected ERM should be $R M S E\left(m_{\mathrm{i}}, m_{\mathrm{e}}\right) / N_{2}, S D\left(d_{2}, d_{2 \mathrm{a}}\right)$, or $S D\left(\mathrm{~d}_{2}, d_{2 \mathrm{a}}\right) / N_{2}$, depending on the appearance of the interference pattern of $T(\lambda)$ and the accuracy of computation of its envelopes. Different ERMs can be used in the computations of the average thickness and the thickness non-uniformity of the film. The proposed approach allows further increasing the accuracy of characterization of thin dielectric and semiconductor films with average thickness of [300,5000] nm by the OEM.

\section{ACKNOWLEDGMENT}

This work was supported by the European Regional Development Fund within the Operational Program "Science and Education for Smart Growth 2014-2020" under 13 the Project CoE "National Center of Mechatronics and Clean Technologies“, Contract No. 14 BG05M2OP001-1.001-0008, L10S7 SynChaLab.

The author expresses gratitude to Dorian Minkov and George Angelov for valuable discussions about the optimizing envelope method.

\section{REFERENCES}

[1]. O. Stenzel, Optical Coatings, Springer, Heidelberg, 2014, p. 5-124.

[2]. D. Minkov, DSc thesis, Characterization of thin films and surface cracks in metals by electromagnetic methods and technologies, Technical University, Sofia, 2018 , p. $30-188$.

[3]. A. Piegari, F. Flory, Optical Thin Films and Coatings, Woodhead Publishing, New Delhi, 2013, p. $26-51$.

[4]. O. Stenzel, The Physics of Thin Film Optical Spectra, Springer, New York, 2005, p. 7-125.

[5]. J.C. Manifacier, J. Gasiot J, J.P. Fillard, A simple method for the determination of the optical constants n, k and the thickness of a weakly absorbing film, J. Phjis. E: Sei. Instrum. 9 (1976) 1002-4.

[6]. D. Poelman, P.J. Smet, Methods for the determination of the optical constants of thin films from single transmission measurements: a critical review, J. Phys. D 36 (2003) 1850-1857.

[7]. M. Brinza, E.V. Emelianova, G.Y. Adriaenssens, Nonexponential distributions of tail states in hydrogenated amorphous silicon Phys. Rev. B 71 (2005) 115209 1-11. 


\section{International Advanced Research Journal in Science, Engineering and Technology}

\section{Vol. 7, Issue 3, March 2020}

[8]. R. Swanepoel, Determination of the thickness and optical constants of amorphous silicon J. Phys. E: Sci. Instrum. 16 (1983) $1214-1222$.

[9]. https://scholar.google.bg/citations?view_op=view_citation\&hl=bg\&user=NKaBMnw AAAAJ\&citation_for_view=NKaBMnwAAAAJ:u-x6o8ySG0sC

[10]. J.M.G. Leal, R.P. Alcon, J.A. Angel, D.A. Minkov, E. Marquez, Influence of substrate absorption on the optical and geometrical characterization of thin dielectric films, Appl. Opt. 41 (2002) 7300-7308.

[11]. D.A. Minkov, G.M. Gavrilov, G.V. Angelov, G.M.D. Moreno, C.G. Vazquez, S.M.F. Ruano, E. Marquez, Optimisation of the envelope method for characterisation of optical thin film on substrate specimens from their normal incidence transmittance spectrum, Thin Solid Films 645 (2018) $370-378$.

[12]. S.C Chiao, B.G. Bovard, H. A. Macleod, Optical-constant calculation over an extended spectral region: application to titanium dioxide film, Appl. Opt. 34 (1995) 7355-7359.

[13]. J.S. Gonzalez, A. D. Parralejo, A.L. Ortiz, F. Guiberteau, Determination of optical properties in nanostructured thin films using the Swanepoel method, Appl. Surf. Sci. 252 (2006) 6013-6017.

[14]. L. Gao, F. Lemarchand, M. Lequime, Refractive index determination of SiO2 layer in the UV/Vis/NIR range: spectrophotometric reverse engineering on single and bi-layer designs, J. Europ. Opt. Soc. Rap. Public. 8 (2013) 13010:1-8.

[15]. S.T. Yen, P.K. Chung, Extraction of optical constants from maxima of fringing reflectance spectra, Appl. Opt. 54 (2015) $663-668$.

[16]. Y. Jin, B. Song, Z. Jia, Y. Zhang, C. Lin, X. Wang, S. Dai, Improvement of Swanepoel method for deriving the thickness and the optical properties of chalcogenide thin films, Opt. Express 25 (2017) 440-451.

[17]. Y. Jin, B. Song, C. Lin, P. Zhang, S. Dai, T. Xu, Q. Nie, Extension of the Swanepoel method for obtaining the refractive index of chalcogenide thin films accurately at an arbitrary wavenumber, Opt. Express 25 (2017) 31273-31280.

[18]. D.A. Minkov, G.V. Angelov, R.N. Nestorov, E. Marquez, E. Blanco, J. J. Ruiz-Perez, Comparative study of the accuracy of characterization of thin films a-Si on glass substrates from their interference normal incidence transmittance spectrum by the Tauc-Lorentz-Urbach, the CodyLorentz-Urbach, the optimized envelopes and the optimized graphical methods, Mater. Res. Express. 6 (2019) 03640:1-15.

[19]. D.A. Minkov, G.M. Gavrilov, J.M.D. Moreno, C.G. Vazquez, E. Marquez, Optimization of the graphical method of Swanepoel for characterization of thin film on substrate specimens from their transmittance spectrum, Meas. Sci. Technol., Meas. Sci. Technol. 28 (2017) 035202.

[20]. L.V.R. DeMarcos, J.I. Larruquert, Analytic optical-constant model derived from Tauc-Lorentz and Urbach tail, Opt. Express. 24 (2016) 28561:112.

[21]. A.S. Ferlauto, G.M. Ferreira, J.M. Pearce, C.R. Wronski, R.W. Collins, X. Deng, G. Ganguly, Analytical model for the optical functions of amorphous semiconductors from the near-infrared to ultraviolet: Applications in thin film photovoltaics, J. Appl. Phys. 92 (2002) $2424-2436$.

[22]. Perkin Elmer, Demonstrating the Accuracy of Transmittance Measurements for High Refractive Index Materials, Perkin Elmer Inc., Oxford, 2010 , p. 4.

[23]. G.M. Gavrilov, D.A. Minkov, E.Marquez, S.M.F. Ruano, Advanced computer drawing envelopes of transmittance spectra of thin film specimens, Int. J. Adv. Res. Sci. Eng. Technol. 3 (2016) 163-168. 